Article

\title{
PFPE Lubricant Molecular Weight Effects on Slider-Disk Interactions
}

\author{
Robert Waltman*, Connie Wiita, Hong Deng, Tushar Suthar, Jose Joseph \\ HGST/Western Digital Company \\ 5601 Great Oaks Parkway, San Jose, CA 95119-1003, USA \\ "Corresponding author: robert.waltman@hgst.com
}

( Manuscript received 31 July 2014; accepted 12 November 2014; published 31 December 2014 )

\begin{abstract}
Slider wear is investigated as a function of D-4OH lubricant film thickness and molecular weight. Slider wear increases with decreasing lubricant film thickness and with increasing molecular weight when compared at the same film thickness in the submonolayer film thickness regime. The two sets of observations are readily interpreted on the basis of the monolayer fraction which corrects the film thickness for the molecular weight-dependent surface coverage.
\end{abstract}

Keywords: perfluoropolyether, slider wear, hard disk drives, boundary lubricant

\section{Introduction}

Today's hard-disk drives (HDDs) employ a 1-2 nm clearance between the read-write element of the low-flying slider and the surface of the rigid magnetic disk. The two moving surfaces are separated by a $1 \mathrm{~nm}$ thick boundary lubricant layer to reduce friction and wear. Low molecular weight perfluoropolyethers (PFPEs) are employed at submonolayer film thicknesses to provide increased dynamic clearance while maintaining lubrication and a low surface energy interface [1-5]. In the submonolayer film thickness regime, confinement and starvation effects limit the long term ability of the PFPE boundary lubricants to keep the two moving surfaces separated during unwanted intermittent contacts. Consequently "slider wear", i.e., the unwanted removal of the carbon film protecting the read/write element of the low-flying slider, becomes a significant determinant of interface durability and tribological robustness. Excessive slider wear causes catastrophic failure in HDDs.

Here we continue to investigate the effects of the PFPE main chain on slider wear. Slider wear and friction are quantified as a function of PFPE molecular weight. Structure-property correlations between disk lubricant and slider wear are identified and discussed. Molecular weight-dependent studies indicate that surface coverage in the submonolayer film thickness regime is a significant determinant of slider wear and friction.

\section{Experimental section}

$\mathrm{D}-4 \mathrm{OH}$ with number average molecular weights

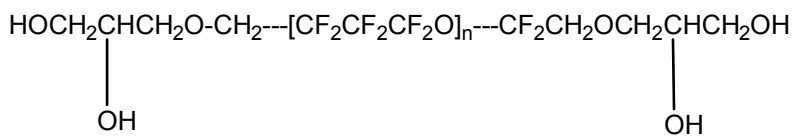

Fig. 1 The chemical structure of D-4OH

$\left(M_{\mathrm{n}}\right)$ equal to 1500 and 2100 were purchased from Moresco (Japan). The chemical structure of D-4OH is shown in Fig. 1. NMR (nuclear magnetic resonance) data characterizing each molecular weight $\left(M_{\mathrm{w}}\right)$ are summarized in Table 1.

Rigid magnetic disks were used as the substrates to study the topically-applied perfluoropolyether (PFPE) thin films. First, a cobalt-based magnetic recording layer $(\mathrm{CoPtCr})$ was sputter-deposited onto smooth glass substrates. Then a $30 \AA$ CVD amorphous carbon film with nitrogen enrichment was next deposited. The carbon film had 12 atom\% $\mathrm{N}$ as quantified by Auger (Perkin-Elmer PHI 660 Scanning Auger Microprobe). For simplicity, this carbon film is referred to as " $\mathrm{CN}_{x}$ " throughout this work. The carbon surface had a RMS

Table 1 NMR data for D-4OH versus $M_{\mathrm{w}}$. The polydispersity $\left(M_{\mathrm{w}} / M_{\mathrm{n}}\right)$ is kindly provided by Moresco

\begin{tabular}{|c|c|c|}
\hline & 1500 & 2100 \\
\hline$\left(\mathrm{CF}_{2} \mathrm{CF}_{2} \mathrm{CF}_{2} \mathrm{O}\right)_{n}, n=$ & 7.4 & 11.3 \\
\hline Tetraol adduct & $97 \%$ & $100 \%$ \\
\hline Dol adduct & $3 \%$ & $0 \%$ \\
\hline$M_{\mathrm{n}}$ & 1500 & 2130 \\
\hline$M_{\mathrm{w}} / M_{\mathrm{n}}$ & 1.03 & 1.04 \\
\hline
\end{tabular}


Table 2 AFM Roughness data for finished disk surface $(1 \mu \mathrm{m} \times 1 \mu \mathrm{m}$ scan $)$ and cyclindrical pin $(10 \mu \mathrm{m} \times 10 \mu \mathrm{m}$ scan $)$. $\mathrm{N}$ represents the number of measurements from which the average data are taken

\begin{tabular}{|c|c|c|}
\hline & $\begin{array}{c}\text { Disk } \\
\mathrm{N}=6\end{array}$ & $\begin{array}{c}\text { Cylindrical Pin } \\
\mathrm{N}=4\end{array}$ \\
\hline$R_{\mathrm{a}}(\mathrm{nm})$ & $0.25 \pm 0.01$ & $45 \pm 9$ \\
\hline$R_{\mathrm{q}}(\mathrm{nm})$ & $0.31 \pm 0.01$ & $57 \pm 13$ \\
\hline$R_{\mathrm{p}}(\mathrm{nm})$ & $1.25 \pm 0.05$ & $247 \pm 109$ \\
\hline$R_{\mathrm{v}}(\mathrm{nm})$ & $1.52 \pm 0.12$ & $264 \pm 76$ \\
\hline
\end{tabular}

roughness $R_{\mathrm{q}}=0.31 \pm 0.01 \mathrm{~nm}$, as measured by AFM (Digital Instruments Dimension 5000). Surface roughness data are summarized in Table 2 and a representative AFM image is shown in Fig. 2. Finally, the lubricant films were topically applied to the carbon surfaces from solvent using a standard dip-coating methodology, using a typical concentration of $0.05 \mathrm{~g} / \mathrm{l}$ and a typical disk withdrawal rate of several $\mathrm{mm} / \mathrm{s}$.

The PFPE lubricant film thicknesses were quantified by specular reflection FTIR (Nicolet Magna Model 560). The FTIR absorption band maximum for each PFPE was correlated to film thickness by XPS (Phi Quantum 2000 ESCA System) using a takeoff angle of $45^{\circ}$ and an electron mean free path of $25 \AA$ [6]. The FTIR-ESCA thickness correlation is shown in Fig. 3.

Side-by-side spin-stand experiments were conducted on finished disks for slider wear. The sliders have a negative pressure ABS design with a center rail head and a fly height of $10 \mathrm{~nm}$. These data were generated on a Kubota HDF2012 spin-stand tester. Slider wear was investigated by on-track continuous sliding for $15 \mathrm{~min}$ under ambient conditions at either a $30 \mathrm{~mW}$ overpush at $5400 \mathrm{rpm}$ or a $20 \mathrm{~mW}$ overpush at $7200 \mathrm{rpm}$, Table 3. By "overpush" is meant the additional thermal

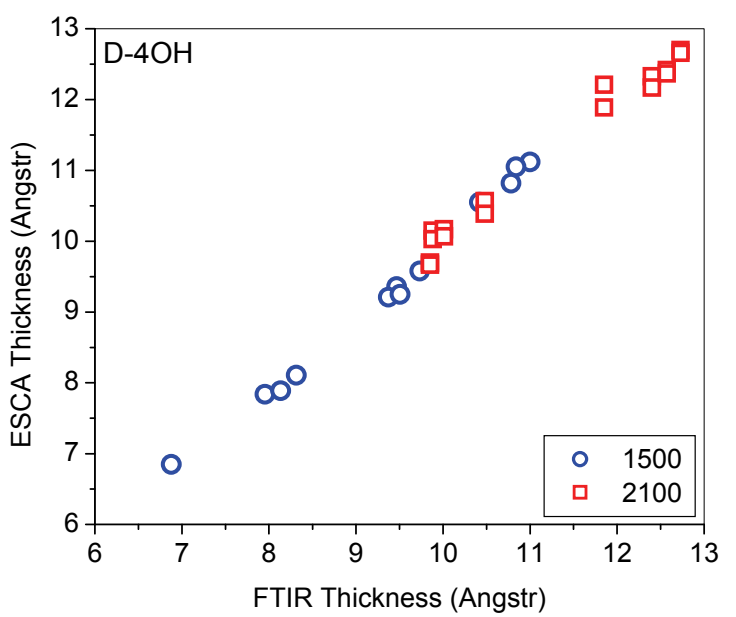

Fig. 3 ESCA versus FTIR film thickness calibration for D-4OH 2100 and 1500 daltons

protrusion of the read/write pole tip to ensure slider-disk contact during the continuous sliding. Initially the touchdown power is measured on a reference track before the continuous sliding wear test begins. The touchdown power required for the pole tip to just contact the reference track is defined as $0 \mathrm{~mW}$ of overpush. After the touchdown power is determined, the slider is moved to a nearby track and the sliding experiment is performed with overpush, Fig. 4 (left). During the continuous sliding, the acoustic emission (AE) is continuously monitored for interface stability. For example, an abrupt change in the AE signal that is associated with a change in sliding friction and hence slider wear rate may be due to unwanted third-body effects [7]. Figure 4 (left) shows that good sliding is obtained for thermal protrusion of $\leq 40 \mathrm{~mW}$. After the continuous sliding experiment is finished $(15 \mathrm{~min}$ duration, see Table 3), the slider is brought back to the reference track and the touchdown power is remeasured. Any resultant change in the touchdown power is assumed to be the result of slider wear. Under flying
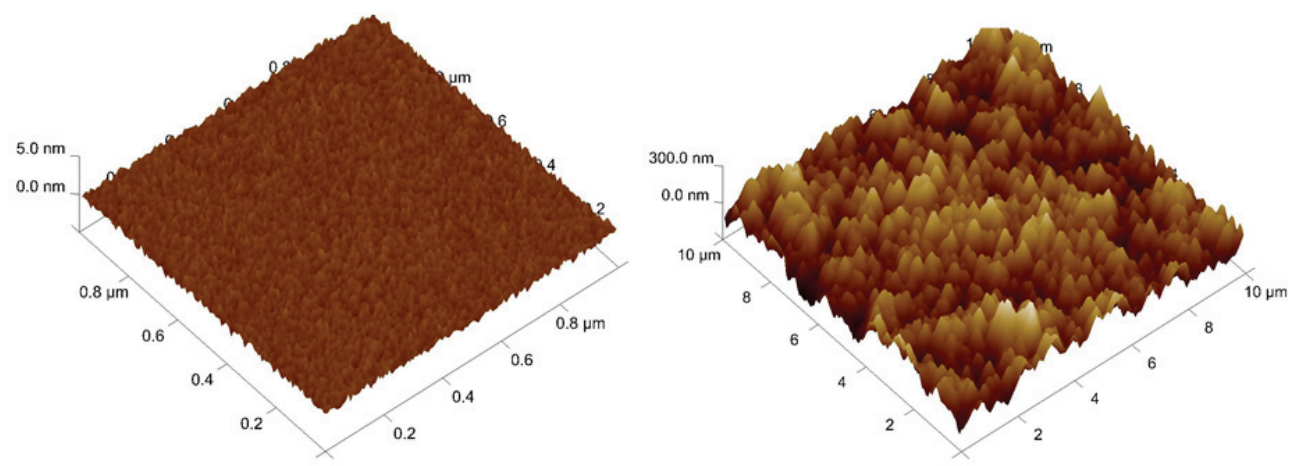

Fig. 2 AFM images of (left) disk surface $(1 \mu \mathrm{m} \times 1 \mu \mathrm{m}$ scan) and (right) pin surface in contact with disk $(10 \mu \mathrm{m} \times 10 \mu \mathrm{m}$ scan $)$ 
Table 3 Spin-stand slider wear test parameters

\begin{tabular}{|c|c|c|c|c|c|}
\hline $\begin{array}{c}\text { Disk } \\
\text { Diameter } \\
(\mathrm{mm})\end{array}$ & $\begin{array}{c}\text { RPM } \\
(\mathrm{rpm})\end{array}$ & $\begin{array}{c}\text { Track Dwell } \\
\text { Time }(\mathrm{min})\end{array}$ & $\begin{array}{c}\text { Pole Tip } \\
\text { Overpush } \\
(\mathrm{mW})\end{array}$ & $\begin{array}{c}\text { Test Radius } \\
(\mathrm{mm})\end{array}$ & $\begin{array}{c}\text { Linear } \\
\text { Displacement } \\
(\mathrm{km})\end{array}$ \\
\hline 95 & 7200 & 15 & 20 & 44 & 30 \\
\hline 65 & 5400 & 15 & 30 & 19 & 10 \\
\hline
\end{tabular}

conditions the change in the touchdown power can be converted to wear rate using a $0.12 \mathrm{~nm} / \mathrm{mW}$ scaling factor for the slider/disk interface used in these studies. All data were generated on identically sputtered disks and the measurements were repeated on four to six separate disks per PFPE sample. The only disk variables investigated here were the PFPE film thickness and molecular weight. These data are summarized in Table 4.

The overpush acts as a load on the disk surface to cause the frictional wear between the two surfaces. While the focal point of these studies is the resultant slider wear, Fig. 4 (right) shows the typical changes observed on the disk surface as a result of the continuous sliding. The ellipsometric images identify both lubricant depletion (lighter region) and lubricant pooling (darker region) in the sliding track [8]. Images after 50 and $30 \mathrm{~mW}$ continuous sliding are shown as illustrative examples for the resultant changes on the disk surface. The $\%$ change in reflectivity is converted to film thickness loss as described in detail previously [9]. Figure 5 shows the typical thickness lost during

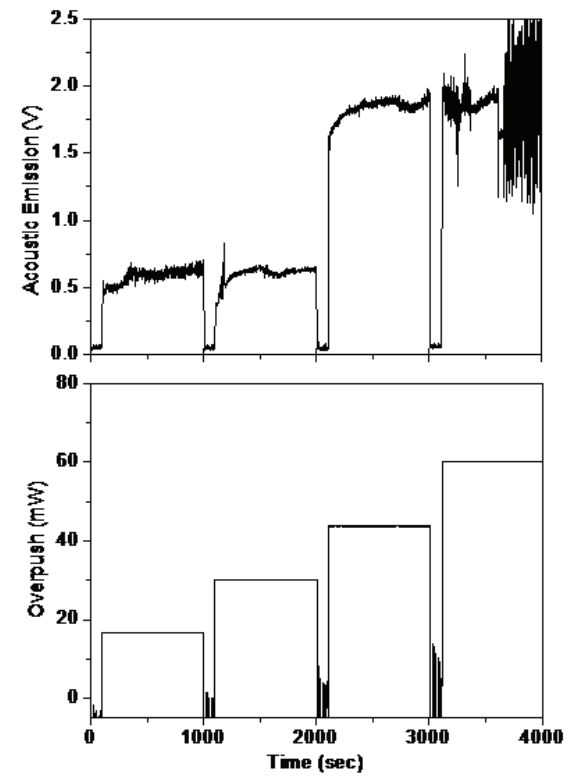

Table 4 Lubricant film thickness data for the spin-stand slider wear tests. The average data represents 4 to 6 measurements per film thickness. The bonded fraction for all samples were $0.75 \pm 0.05$

\begin{tabular}{|c|c|c|c|}
\hline $\begin{array}{c}\text { Overpush } \\
(\mathrm{mW})\end{array}$ & $\begin{array}{c}\mathrm{D}-4 \mathrm{OH} \\
M_{\mathrm{n}}\end{array}$ & $\begin{array}{c}\mathrm{D}-4 \mathrm{OH} \\
\text { Thickness }(\AA)\end{array}$ & $\begin{array}{c}\text { Monolayer } \\
\text { Fraction }\end{array}$ \\
\hline 20 & 2100 & $9.64 \pm 0.86$ & $0.52 \pm 0.05$ \\
\hline 20 & 2100 & $11.31 \pm 0.31$ & $0.61 \pm 0.02$ \\
\hline 20 & 2100 & $12.54 \pm 0.31$ & $0.68 \pm 0.02$ \\
\hline 20 & 1500 & $8.00 \pm 0.52$ & $0.56 \pm 0.04$ \\
\hline 20 & 1500 & $9.42 \pm 0.15$ & $0.66 \pm 0.01$ \\
\hline 20 & 1500 & $10.76 \pm 0.22$ & $0.76 \pm 0.02$ \\
\hline 30 & 2100 & $9.24 \pm 0.19$ & $0.50 \pm 0.04$ \\
\hline 30 & 2100 & $11.16 \pm 0.12$ & $0.60 \pm 0.04$ \\
\hline 30 & 2100 & $12.15 \pm 0.18$ & $0.66 \pm 0.05$ \\
\hline 30 & 2100 & $13.78 \pm 0.14$ & $0.74 \pm 0.05$ \\
\hline 30 & 1500 & $8.07 \pm 0.42$ & $0.57 \pm 0.03$ \\
\hline 30 & 1500 & $10.12 \pm 0.15$ & $0.71 \pm 0.02$ \\
\hline 30 & 1500 & $11.29 \pm 0.27$ & $0.80 \pm 0.02$ \\
\hline 30 & 1500 & $11.91 \pm 0.06$ & $0.84 \pm 0.01$ \\
\hline
\end{tabular}
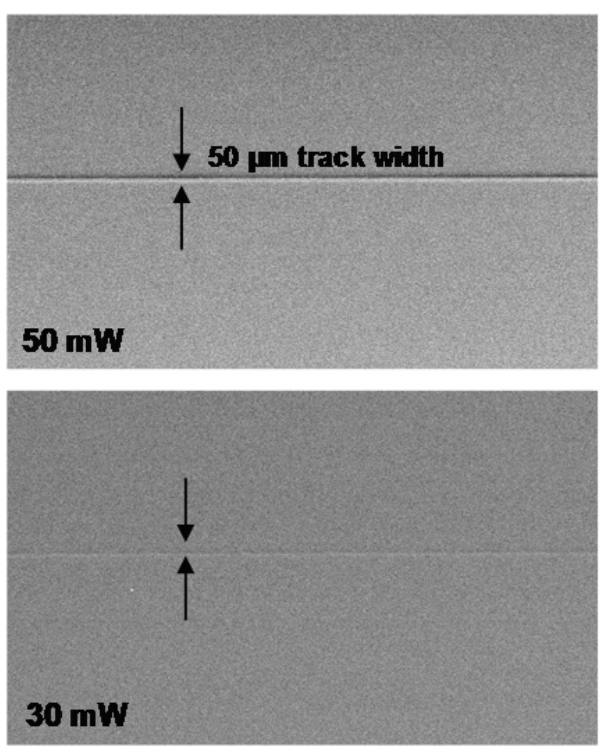

Fig. 4 A summary of the head wear experiment for D-4OH 1500 as a function of overpush. (Left, top) Acoustic emission as a function of continuous sliding $(7200 \mathrm{rpm})$ for 20, 30, 40 and 50 $\mathrm{mW}$ overpush. (Left, bottom) The applied overpush $(\mathrm{mW})$ during the continuous sliding test corresponding to the left top figure. (Right) Representative OSA (optical surface analyzer) image of the disk surface after the 15 min continuous sliding at 30 and $50 \mathrm{~mW}$ overpush. The slided track is located between the arrows. The OSA images were all captured within 10-15 min after sliding to minimize the effects of PFPE reflow into the tracks 

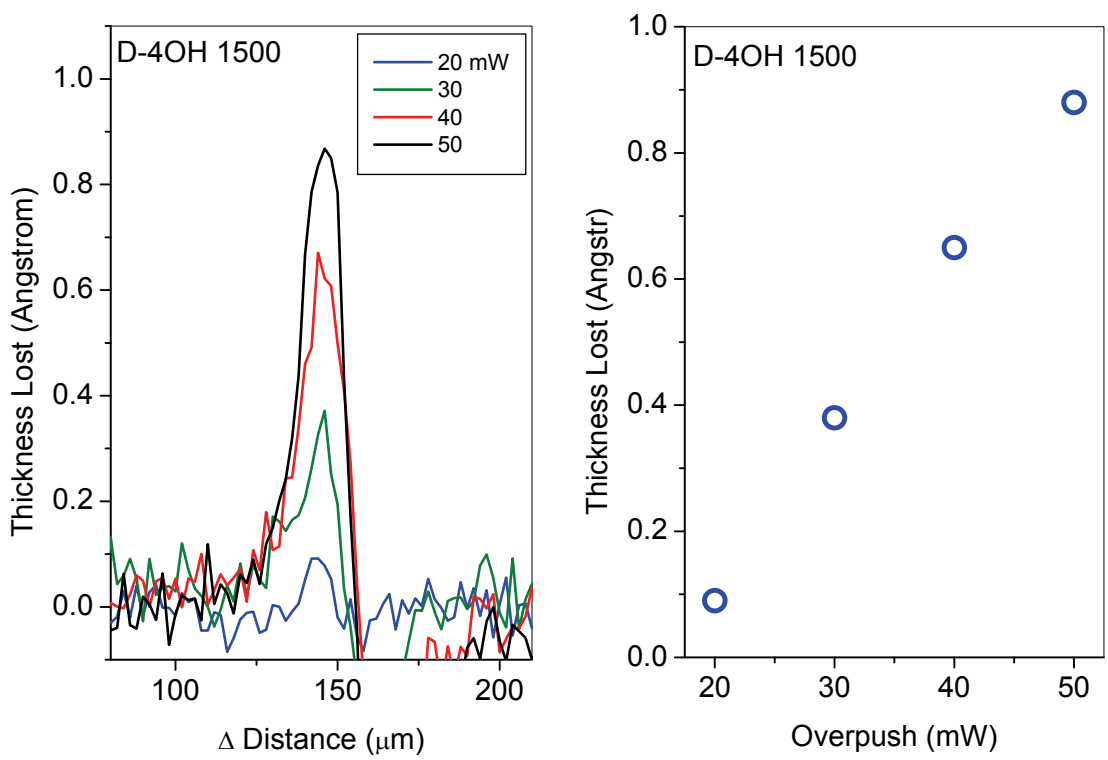

Fig. 5 D-4OH 1500 film thickness loss from the continuous sliding test as a function of overpush (mW)

the sliding test for $10 \AA \mathrm{D}-4 \mathrm{OH}(1500)$ as a function of overpush. Lubricant depletion in the track is approximately 0.1 and $0.4 \AA$ for the 20 and $30 \mathrm{~mW}$ overpush used in these experiments, respectively.

Friction force was measured as a completely separate experiment from the head wear test using a 2.5 $\mathrm{mm}$ diameter cylindrical pin (aluminum oxide surface) on the rotating disk surface $(5 \mathrm{~m} / \mathrm{s})$ as a function of load $(0.44,0.59$ and $1.03 \mathrm{~N})$. The friction force is measured at $20^{\circ} \mathrm{C}$ and $50 \% \mathrm{RH}$. The loads used here are much larger than those used in the slider wear tests. In order to render the results of the two different experiments comparable, the coefficient of friction is also reported.
The coefficient of friction is quantified by the ratio of the frictional force to the load force on the pin. One transducer measures the force applied to the rotating disk surface and a second transducer measures the resultant tangential force applied to the load arm (deflection) while the force is applied to the rotating disk. The transducers are calibrated using weights between 0 and 250 grams. The friction force reported here is taken at the asymptotic limit of the friction versus time experiment. A simplified experimental diagram and a typical friction force curve are shown in Fig. 6. The roughness of the pin surface is quantified in Table 2 and a representative AFM image is shown in Fig.
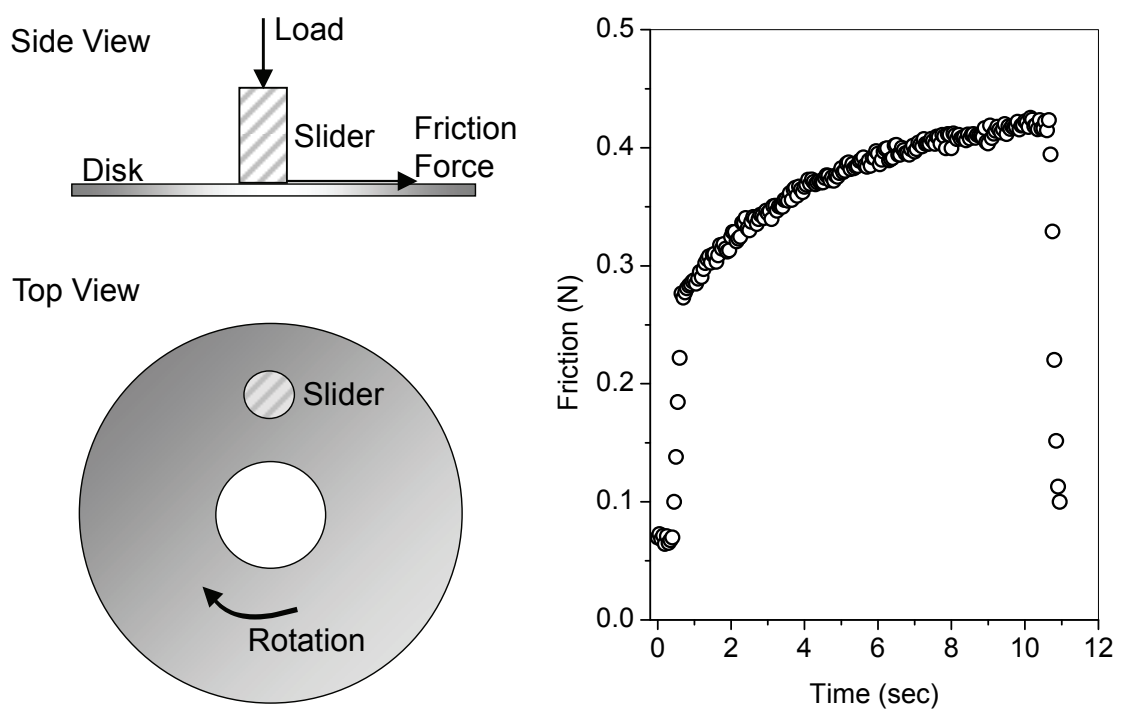

Fig. 6 Experimental diagram for the friction test (left) and a representative friction force curve as a function of time. All friction force values are taken at the asymptotic value 
2. A useful estimate for identifying the operating tribological regime is defined as the ratio of the lubricant film thickness and the composite surface roughness [10]:

$$
\Lambda=\frac{h}{\sqrt{R_{\mathrm{q}, \mathrm{a}}^{2}+R_{\mathrm{q}, \mathrm{b}}^{2}}}
$$

$h$ is the lubricant film thickness, and $R_{q, a}$ and $R_{q, b}$ are the root mean square roughness of the two surfaces (Table 2), respectively. For the 8-12 $\AA$ PFPE lubricant films used in these studies, Table $5, \Lambda<0.1$ and thus friction coefficients consistent with the boundary lubrication regime is expected.

\section{Results}

The slider wear rate as a function of lubricant film thickness and of molecular weight are shown in Fig. 7 at $20 \mathrm{~mW}$ (top) and $30 \mathrm{~mW}$ overpush (bottom). Under both experimental conditions (Table 3 ), slider wear rate is observed to decrease linearly with increasing lubricant film thickness in the film thickness range investigated (Table 4). At $20 \mathrm{~mW}$ overpush the head wear rate per film thickness change are a nearly identical -0.0094 and $-0.0098 \mathrm{pm} /$ cycle $/ \AA$ for $\mathrm{D}-4 \mathrm{OH}$ 2100 and 1500 , respectively, while at the larger $30 \mathrm{~mW}$ overpush, the head wear rates per thickness are a significantly larger -0.025 and $-0.082 \mathrm{pm} /$ cycle $/ \AA$ for $\mathrm{D}-4 \mathrm{OH} 2100$ and 1500 , respectively. At $30 \mathrm{~mW}$ overpush the lower molecular weight D-4OH 1500 exhibits a larger head wear rate per thickness change than D-4OH 2100. Thus structure-property correlations are better revealed when head wear experiments are conducted as a function of overpush. The molecular weight effect on head wear will be discussed in more detail below. For now we observe that as the film thickness increases or the load decreases (20 vs $30 \mathrm{~mW}$ overpush), slider wear decreases as expected on the basis of the Stribeck Curve.

The measured friction forces $(F)$ as a function of load $(L)$ for D-4OH 2100 and 1500 are summarized in Table 5. For each $L$, three lubricant film thicknesses are evaluated for each molecular weight. Figure 8 (top) shows a summary plot of the measured friction force as a function of load for all data contained in Table 5. Thus the average friction force taken from all three film thicknesses per $L$ is combined. Here the error bars associated with the friction force include the dependence of the friction force on film thickness. In the bottom graph, the friction force is plotted as a function of $L$ for D-4OH 2100 and 1500 corresponding to the nearly identical monolayer fraction of $0.60 \pm 0.01$ (Table 5). In both cases $F$ is found to be proportional to $L$ obeying Amonton's law:

$$
F=\mu L
$$

Since the data do not extrapolate to the origin, the friction coefficient $\mu$ is defined by the slope, i.e., $\mu=$ $\mathrm{d} F / \mathrm{d} L$. Thus $\mu=0.90 \pm 0.09$ and $0.81 \pm 0.08$ for $\mathrm{D}-4 \mathrm{OH}$ 2100 and 1500, respectively, in the top graph, and $\mu=$ $0.94 \pm 0.05$ and $0.78 \pm 0.07$ for D-4OH 2100 and 1500 , respectively, in the bottom graph. The two sets of data are not significantly different. For polymer films in excess of the monolayer film thickness, the friction

Table 5 Friction force versus D-4OH film thickness, molecular weight and applied load. The average data represents 4 to 6 measurements per experimental condition. The bonded fraction for all samples were $0.75 \pm 0.05$

\begin{tabular}{|c|c|c|c|c|c|}
\hline Load $(\mathrm{N})$ & $\begin{array}{c}\mathrm{D}-4 \mathrm{OH} \\
M_{\mathrm{n}}\end{array}$ & $\begin{array}{c}\mathrm{D}-4 \mathrm{OH} \\
\text { Thickness }(\AA)\end{array}$ & $\begin{array}{c}\text { Monolayer } \\
\text { Fraction }\end{array}$ & Friction $(\mathrm{N})$ & $1 / \mu$ \\
\hline 0.44 & 2100 & $9.37 \pm 0.24$ & $0.51 \pm 0.01$ & $0.61 \pm 0.01$ & $0.75 \pm 0.04$ \\
\hline 0.44 & 2100 & $11.00 \pm 0.46$ & $0.59 \pm 0.03$ & $0.50 \pm 0.03$ & $0.87 \pm 0.05$ \\
\hline 0.44 & 2100 & $12.51 \pm 0.11$ & $0.68 \pm 0.01$ & $0.46 \pm 0.03$ & $0.97 \pm 0.05$ \\
\hline 0.44 & 1500 & $8.59 \pm 0.57$ & $0.61 \pm 0.04$ & $0.61 \pm 0.02$ & $0.72 \pm 0.02$ \\
\hline 0.44 & 1500 & $9.93 \pm 0.37$ & $0.70 \pm 0.03$ & $0.53 \pm 0.02$ & $0.84 \pm 0.02$ \\
\hline 0.44 & 1500 & $11.39 \pm 0.19$ & $0.80 \pm 0.01$ & $0.48 \pm 0.01$ & $0.93 \pm 0.02$ \\
\hline 0.59 & 2100 & $9.37 \pm 0.24$ & $0.51 \pm 0.01$ & $0.73 \pm 0.03$ & $0.81 \pm 0.03$ \\
\hline 0.59 & 2100 & $11.00 \pm 0.46$ & $0.59 \pm 0.03$ & $0.66 \pm 0.03$ & $0.90 \pm 0.04$ \\
\hline 0.59 & 2100 & $12.51 \pm 0.11$ & $0.68 \pm 0.01$ & $0.55 \pm 0.03$ & $1.07 \pm 0.06$ \\
\hline 0.59 & 1500 & $8.59 \pm 0.57$ & $0.61 \pm 0.04$ & $0.78 \pm 0.03$ & $0.75 \pm 0.03$ \\
\hline 0.59 & 1500 & $9.93 \pm 0.37$ & $0.70 \pm 0.03$ & $0.68 \pm 0.03$ & $0.87 \pm 0.04$ \\
\hline 0.59 & 1500 & $11.39 \pm 0.19$ & $0.80 \pm 0.01$ & $0.56 \pm 0.03$ & $1.04 \pm 0.05$ \\
\hline 1.03 & 2100 & $9.64 \pm 0.86$ & $0.52 \pm 0.05$ & $1.09 \pm 0.02$ & $0.95 \pm 0.02$ \\
\hline 1.03 & 2100 & $11.31 \pm 0.31$ & $0.61 \pm 0.02$ & $1.06 \pm 0.02$ & $0.98 \pm 0.02$ \\
\hline 1.03 & 2100 & $12.54 \pm 0.31$ & $0.68 \pm 0.02$ & $0.99 \pm 0.05$ & $1.04 \pm 0.03$ \\
\hline 1.03 & 1500 & $8.00 \pm 0.52$ & $0.56 \pm 0.04$ & $1.09 \pm 0.06$ & $0.94 \pm 0.06$ \\
\hline 1.03 & 1500 & $9.42 \pm 0.15$ & $0.66 \pm 0.01$ & $1.04 \pm 0.04$ & $0.99 \pm 0.04$ \\
\hline 1.03 & 1500 & $10.76 \pm 0.22$ & $0.76 \pm 0.02$ & $0.93 \pm 0.04$ & $1.10 \pm 0.05$ \\
\hline
\end{tabular}



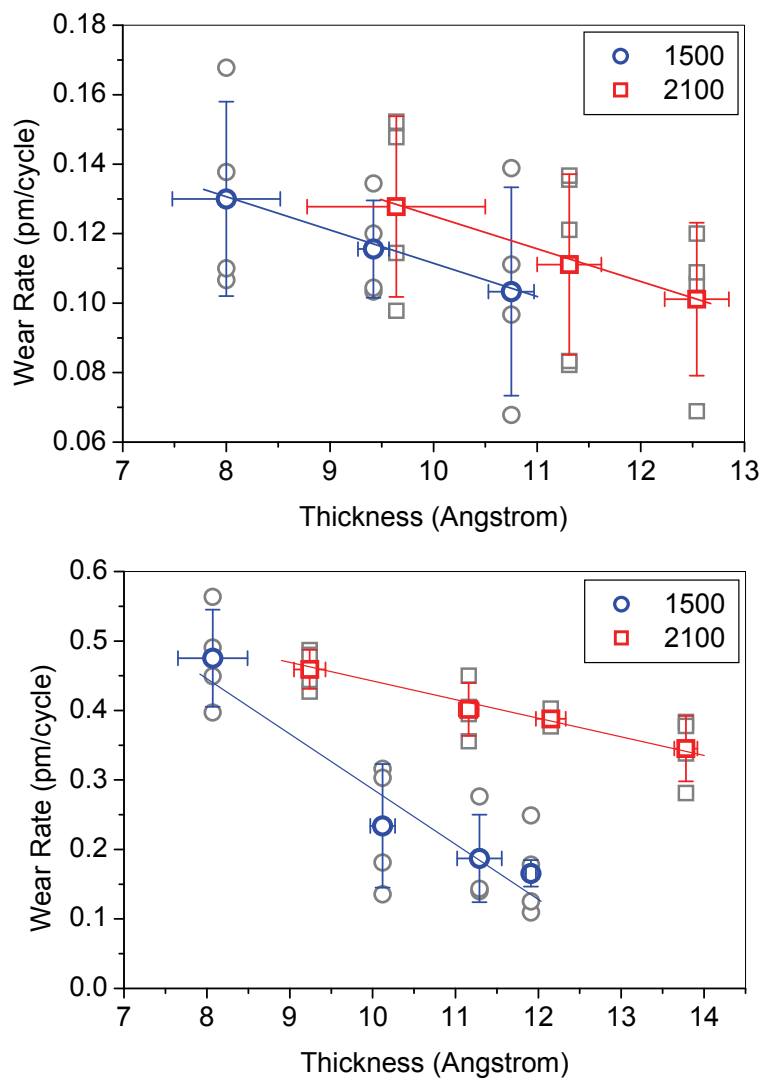

Fig. 7 The slider wear rate as a function of $\mathrm{D}-4 \mathrm{OH}$ film thickness and molecular weight. (Top) 20 $\mathrm{mW}$ overpush; (bottom) $30 \mathrm{~mW}$ overpush. The error bars $( \pm 1 \sigma)$ represent the average results from four to six slider wear rate measurements

coefficient usually decreases with increasing molecular weight for specific polymer types [11]. Longer chains require a higher pressure to be squeezed out from between two surfaces rendering the film more fully packed thereby providing for a lower coefficient of friction [11]. Long chain molecules also inhibit solvation (or discretized contact drainage) that improves friction [12]. For the submonolayer films investigated here, the molecular weight differences (2100 vs 1500 daltons) are perhaps not large enough to impose on $\mu$. We do observe that both molecular weights show a finite friction force at zero load, indicative of adhesive surfaces. The relatively larger zero-load friction force for the lower molecular weight $\mathrm{D}-4 \mathrm{OH}$ is attributed to its larger molecular polarity $[13,14]$.

The friction coefficient of $\sim 0.9$ as quantified here is consistent with PFPE $\mu$ values previously determined at both macro- and nano-scales. Macroscale PFPE $\mu$ values of 0.04 to 0.7 [15-20] and nanoscale PFPE $\mu$ values of 0.01 to 1 [11,21-24] have been reported. Coefficient of friction values are supposedly scale-dependent and have smaller values at nanoscale
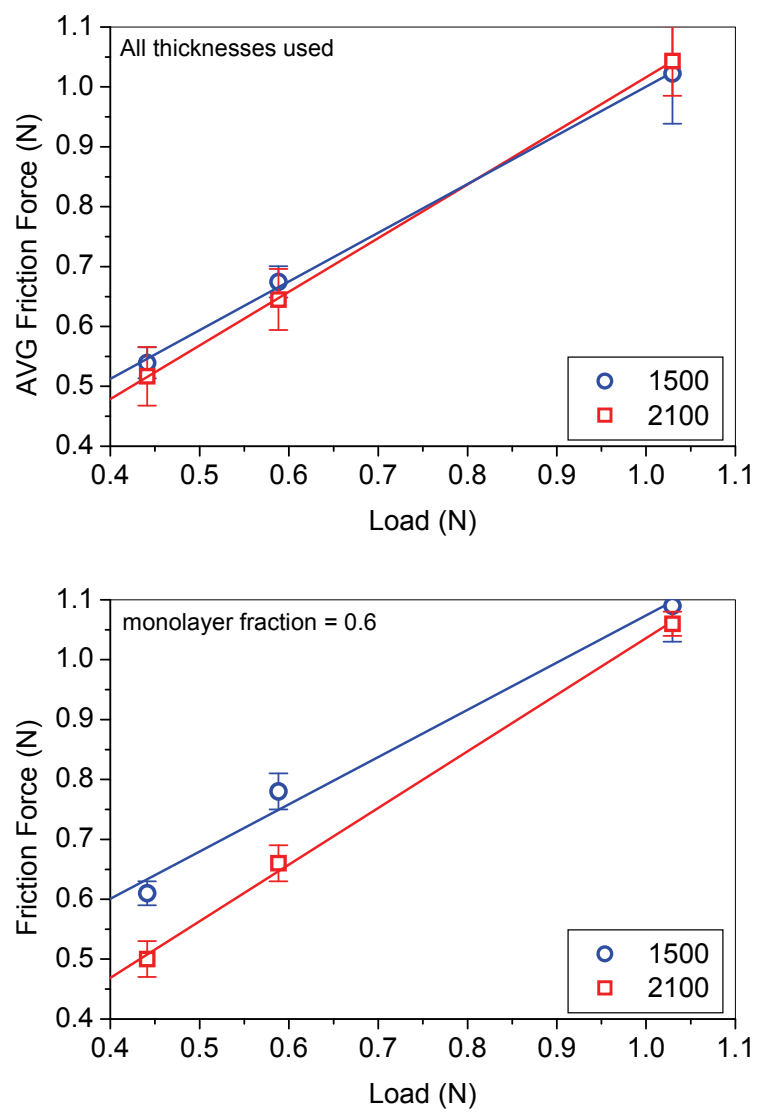

Fig. 8 Friction force as a function of load for D-4OH 2100 and 1500 daltons. (Top) Data includes all film thickness listed in Table 5. (Bottom) Data is for monolayer fraction of $0.6 \pm 0.1$ which correspond to approximately $11 \AA$ of $\mathrm{D}-4 \mathrm{OH} 2100$ and $8.5 \AA$ of $\mathrm{D}-4 \mathrm{OH}$ 1500 as listed in Table 5. The error bars $( \pm$ $1 \sigma$ ) represent the average results from four to six friction measurements

dimensions due to the smaller contact areas and loads [23]. The range of macro- and nano-scale $\mu$ values reported in the literature for PFPEs appear to span several orders of magnitude so the $\mu$ values reported herein appear to be within PFPE expectation values. PFPE film thicknesses and molecular weights are significant determinants so the larger $\mu$ values reported here could be the additional result of having used submonolayer film thicknesses and extremely lower molecular weights in addition to having conducted the friction measurements at macroscale.

The friction force as a function of $\mathrm{D}-4 \mathrm{OH}$ film thickness and molecular weight are shown in Fig. 9. These disks are identical to those used in the slider wear experiments shown previously in Fig. 7. The friction force increases approximately linearly with decreasing film thickness in both cases, as observed similarly for the slider wear rates per thickness. The slopes are $0.027 \pm 0.010$ and $-0.063 \pm 0.015 \mathrm{~N} / \AA \AA$ for $\mathrm{D}-4 \mathrm{OH} 2100$ 
and 1500 , respectively. The friction force per thickness change is larger for the lower molecular weight $\mathrm{D}-4 \mathrm{OH}$, much as observed for the slider wear rate per thickness change at the $30 \mathrm{~mW}$ overpush condition.

\section{Discussion}

The results discussed above indicate similar slider wear rates per thickness for D-4OH 2100 and 1500 at the lower $20 \mathrm{~mW}$ overpush but a significantly larger slider wear rate per thickness for the lower molecular weight $\mathrm{D}-4 \mathrm{OH} 1500$ at the higher $30 \mathrm{~mW}$ overpush (Fig. 7). The friction force per thickness was also larger for the lower molecular weight D-4OH 1500 (Fig. 9). These data must be reconciled with the observation that the friction coefficient $\mu(\mathrm{d} F / \mathrm{d} L)$ was very similar for D-4OH 2100 and 1500 (Fig. 8 top).

The most significant differences between D-4OH 2100 and 1500 are the following. First, the monolayer thicknesses are different and that directly affects surface coverage for the submonolayer films. Second, the molecular polarity increases with decreasing $\mathrm{D}-4 \mathrm{OH}$ molecular weight and that affects the adsorbed film structure and the interfacial surface energy [9]. For example, load carrying capacity in the contact and friction are strong functions of solvation effects and molecular chain lengths $[11,12]$. Here we interpret the head wear and friction force data strictly on the basis of surface coverage by the PFPE lubricant.

The monolayer thickness for $\mathrm{D}-4 \mathrm{OH}$ as a function of molecular weight is summarized in Table 6. These data are discussed in detail elsewhere [9] so no extensive reiteration is necessary here. We replot the slider wear versus film thickness data shown previously in Fig. 7 as slider wear versus monolayer fraction in Fig. 10 by dividing the film thickness by the monolayer thickness given in Table 6 . The corresponding monolayer fractions are summarized in Table 5. When

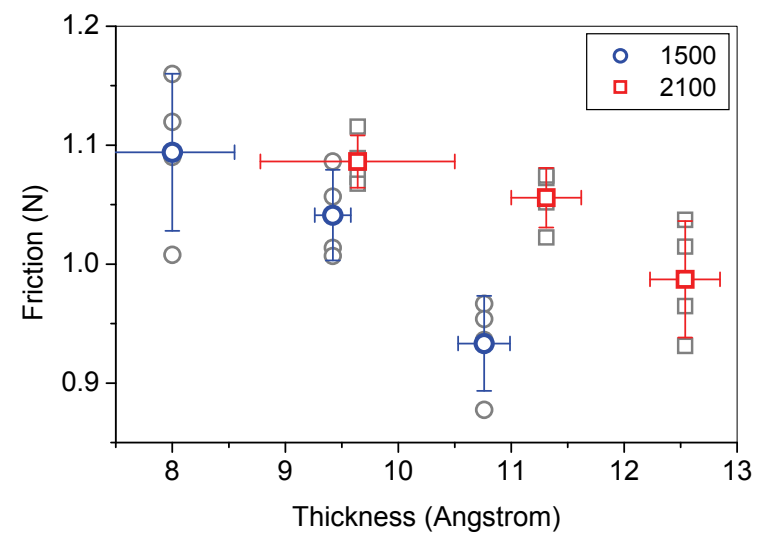

Fig. 9 Friction force a function of $\mathrm{D}-4 \mathrm{OH}$ film thickness and molecular weight. Load $=1 \mathrm{~N}$. The error bars $( \pm 1 \sigma)$ represent the average results from four to six friction measurements
Table 6 The average monolayer thickness for D-4OH versus $M_{\mathrm{w}}$ [9]

\begin{tabular}{|c|c|c|}
\hline $\mathrm{D}-4 \mathrm{OH}$ & 1500 & 2100 \\
\hline $\mathrm{AVG}$ & $14.2 \pm 0.2 \AA$ & $18.5 \pm 1.3 \AA$ \\
\hline
\end{tabular}

the slider wear rate for both the 20 and $30 \mathrm{~mW}$ overpush data are plotted as a function of monolayer fraction, the wear rate appears to fall on the same line indicative that surface coverage is the significant determinant in the submonolayer film thickness regime. A similar correlation between slider wear and lubricant coverage based on the dispersive surface energy was recently developed by Tani et al [24].

The friction force data can be similarly treated. When the friction force versus film thickness shown previously in Fig. 9 is re-plotted as friction force versus monolayer fraction in Fig. 11, the friction force scales with coverage and is independent of molecular weight (between 1500 and 2000 daltons). Since the friction data is correlated to surface coverage for PFPE films in the
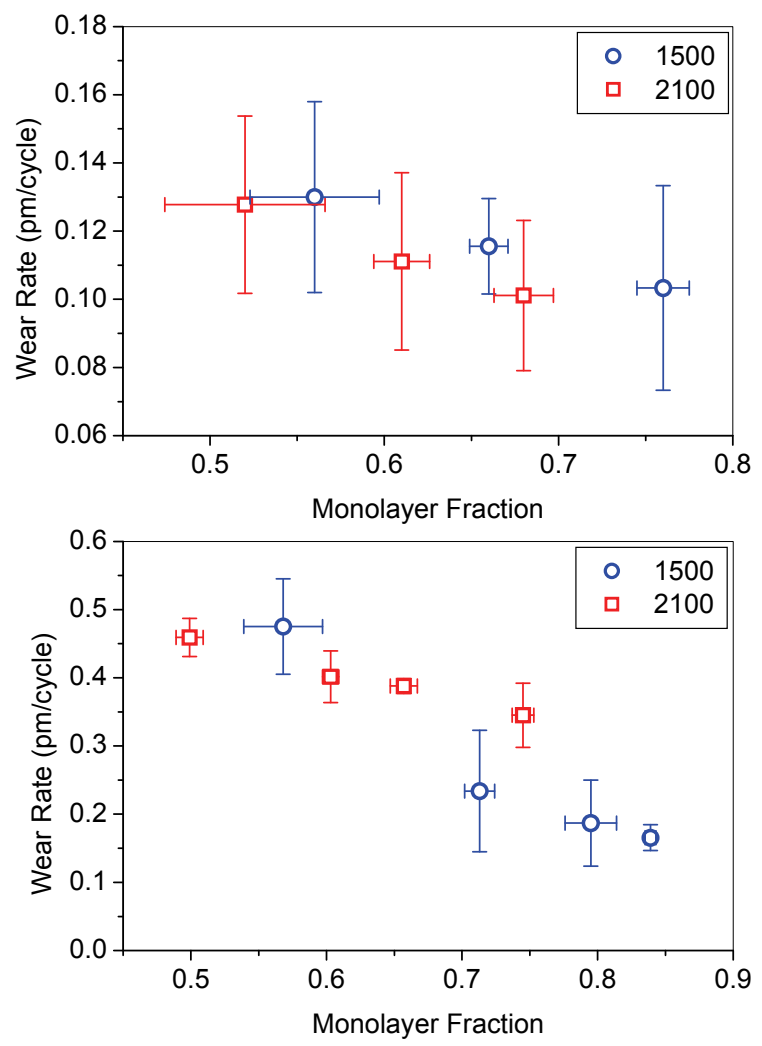

Fig. 10 The slider wear rate as a function of D-4OH monolayer fraction and molecular weight. (Top) $20 \mathrm{~mW}$ overpush; (bottom) $30 \mathrm{~mW}$ overpush. The monolayer fraction is the film thickness divided by the monolayer thickness (Table 6). The error bars $( \pm 1 \sigma)$ represent the average results from four to six slider wear rate measurements 


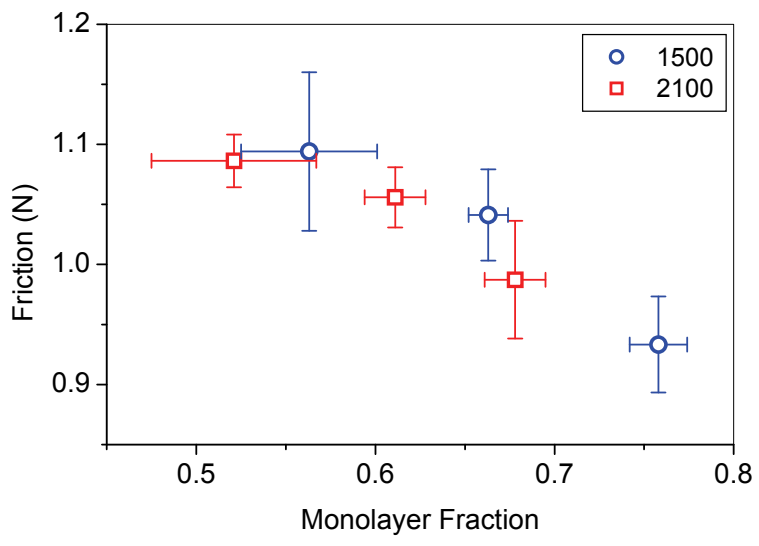

Fig. 11 Friction force a function of $\mathrm{D}-4 \mathrm{OH}$ monolayer fraction and molecular weight. Load $=1 \mathrm{~N}$. The monolayer fraction is the film thickness divided by the monolayer thickness (Table 6). The error bars $( \pm 1 \sigma)$ represent the average results from four to six friction measurements

submonolayer regime, the similar friction coefficient $\mu$ values previously shown in Fig. 8 (top) can now be understood.

Additionally, since the slider wear rate and friction both increase with decreasing coverage, it is reasonable to expect that slider wear rate increases with friction [25]. The volumetric wear $W_{\mathrm{v}}$ is related to the normal load $L$ as [26]:

$$
W_{\mathrm{v}}=k L d
$$

$k$ is a wear coefficient and $d$ is the sliding distance. For two surfaces sliding against one another, the wear volume is proportional to the normal load and the sliding distance. Since $k$ is proportional to $\mu$ [27], wear volume should increase with friction. Figure 12 shows that the slider wear rate is proportional to the friction

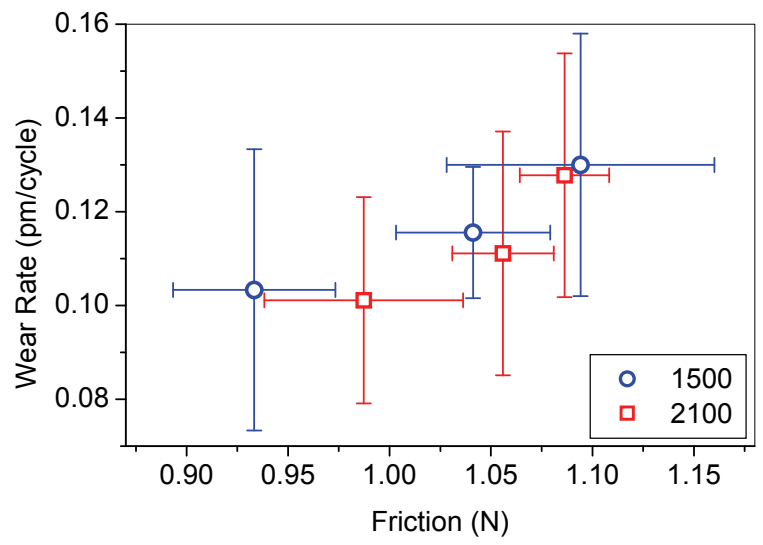

Fig. 12 The slider wear rate as a function of D-4OH friction compiled from Figs. 9 and 10 force.

The data presented above indicate that a lower molecular weight lubricant can be utilized at a lower film thickness to provide a similar slider wear rate or friction force as a thicker, larger molecular weight PFPE lubricant when normalized to coverage or the monolayer fraction. This has several advantages. First, slider-disk spacing is gained by reducing the PFPE molecular weight [1] such that in today's low-flying HDDs, an increased margin is provided against early unwanted slider-disk interactions. Second, at the same film thickness, lower molecular weight lubricants provide better coverage as discussed in detail above. This is important when coverage-related properties of the interface such as increased resistance to slider wear and contamination adsorption are simultaneously required.

\section{Conclusions}

Slider wear increases with decreasing lubricant film thickness. Slider wear, when compared at the same film thickness, increases with increasing molecular weight. The two sets of observations are readily interpreted on the basis of the monolayer fraction which corrects differences in the absolute film thickness for the molecular weight-dependent surface coverage in the submonolayer film thickness regime.

\section{References}

[1] Khurshudov, A. and Waltman, R. J., "The Contribution of Thin PFPE Lubricants to Slider-Disk Spacing," Tribol. Lett., 11, 2001, 143-149.

[2] Waltman, R. J., Raman, V. and Burns, J., "The Contribution of Thin PFPE Lubricants to Slider-Disk Spacing. 3. Effect of Main Chain Flexibility," Tribol. Lett., 17, 2004, 239-244.

[3] Guo, X.-C., Knigge, B., Marchon, B., Waltman, R. J., Carter, M. and Burns, J., "Multidentate Functionalized Lubricant for Ultralow Head/Disk Spacing in a Disk Drive,” J. Appl. Phys., 100, 2006, 044306-1-044306-8.

[4] McGuiggan, P. M., "Friction and Adhesion Measurements between a Fluorocarbon Surface and a Hydrocarbon Surface in Air," J. Adhesion, 80, 2004, 395-408.

[5] Sills, S. and Overney, R. M., "Creeping Friction Dynamics and Molecular Dissipation Mechanisms in Glassy Polymers," Phys. Rev. Lett., 91, 2003, 095501-1-095501-4.

[6] Toney, M. F., Mate, C. M. and Pocker, D. J., "Calibrating ESCA and Ellipsometry Measurements of Perfluoropolyether Lubricant Thickness," IEEE Trans. Magn., 34, 1998, 1774-1776. 
[7] Khurshudov, A. and Waltman, R. J., "Tribology Challenges of Modern Magnetic Hard Disk Drives," Wear, 251, 2001, 1124-1132.

[8] Khurshudov, A., Baumgart, P. and Waltman, R. J., "In Situ Quantitative Analysis of Nanoscale Lubricant Migration at the Slider-Disk Interface," Wear, 225-229, 1999, 690-699.

[9] Waltman, R. J., "The Adsorbed Film Structure of End-Functionalized Poly(Perfluoro-n-Propylene Oxide)," Tribol. Online, 9, 2014, 113-120.

[10] Martin, C. L., Ajayi, O. O., Torrel, S., Fenske, G. R. and Erck, R. A., "Experimental Investigation of Transition in Lubrication Regime for Thin-Film Coated Surfaces," Proc. ASME/STLE 2012 Int. Joint Tribol. Session, Manuscript No. IJTC2012, 2012, 1-3.

[11] McGuiggan, P. M., Gee, M. L., Yoshizawa, H., Hirz, S. J. and Israelachvilli, J. N., "Friction Studies of Polymer Lubricated Surfaces," Macromolecules, 40, 2007, 2126-2133.

[12] Chong, W. W. F., Teodorescu, M. and Rahnejat, H., "Effect of Lubricant Molecular Rheology on Formation and Shear of Ultra-Thin Surface Films," J. Phys. D: Appl. Phys., 44, 2011, 165302-1-165302-11.

[13] Tani, H., Mitsutome, T. and Tagawa, N., "Adhesion and Friction Behavior of Magnetic Disks with Ultrathin Perfluoropolyether Lubricant Films Having Different End-Groups Measured Using Pin-On Disk Test," IEEE Trans. Magn., 49, 2013, 2638-2644.

[14] Waltman, R. J. and Guo, X.-C., "AFM Force-Distance Curves for Perfluoropolyether Boundary Lubricant Films as a Function of Molecular Polarity," Tribol. Lett., 45, 2012, 275-289.

[15] Zhao, W., Zhu, M., Mo, Y. and Bai, M., "Effect of Anion on Micro/Nano-Tribological Properties of Ultra-Thin Imidazolium Ionic Liquid Films on Silicon Wafer," Colloids Surf. A: Physicochem. Eng. Aspects, 332, 2009, 78-83.

[16] Satyanarayana, N., Sinha, S. K. and Ong, B. H., "Tribology of a Novel UHMWPE/PFPE Dual
Film Coated onto Si Surface," Sens. Actu. A, 128, 2006, 98-108.

[17] Gu, G., Shen, X. and Qing, F.-L., "Preparation and Tribological Performance of Perfluoropolyether Derived Coatings," Appl. Surf. Sci., 253, 2007, 6980-6986.

[18] Leong, J. Y., Satyanarayana, N. and Sinha, S. K., "A Tribological Study of Multiply-Alkylated Cyclopentanes and Perfluoropolyether Lubricants for Application to Si-MEMS Devices," Tribol. Lett., 50, 2013, 195-206.

[19] Kondo, H., "Ionic Liquid Lubricant with Ammonium Salts for Magnetic Media," in "Applications of Ionic Liquids in Science and Technology," Handy, S., Ed., InTech 2011, Chapter 20.

[20] Zhang, X. H., Gates, R. S., Anders, S. and Hsu, S. M., "An Accelerated Wear Test Method to Evaluate Lubricant Thin Films on Magnetic Hard Disks," Tribol. Lett., 11, 2001, 15-21.

[21] Chen, C.-Y., Bogy, D. and Bhatia, C. S., "Effect of Lubricant Bonding Fraction at the Head-Disk Interface," Tribol. Lett., 10, 2001, 195-201.

[22] Sinha, S. K., Kawaguchi, M. and Kato, T., "Surface Profiles and Modulation of Ultra-Thin Perfluoropolyether Lubricant in Contact Sliding," J. Phys. D: Appl. Phys., 37, 2004, 2247-2255.

[23] Bhushan, B., "Nanotribology and Nanomechanics," Wear, 259, 2005, 1507-1531.

[24] Kobayashi, N., Tani, H., Shimizu, T., Koganezawa, S. and Tagawa, N., "Slider Wear on Disks Lubricated by Ultra-Thin Perfluoropolyether Lubricants with Different Molecular Weights," Tribol. Lett., 53, 2014, 43-49.

[25] Kato, K., "Wear in Relation to Friction - A Review," Wear, 241, 2000, 151-157.

[26] Maru, M. M. and Tanaka, D. K., "Consideration of Stribeck Diagram Parameters in the Investigation on Wear and Friction Behavior in Lubricated Sliding,” J. Braz. Soc. Mech. Sci. Eng., 29, 2007, 55-62.

[27] Rabinowicz, E., "The Relation between Friction and Wear for Boundary-Lubricated Surfaces," Proc. Phys. Soc. B, 68, 1955, 603-608. 